\title{
Clinical outcome and cost analysis of negative pressure wound therapy in extremity wounds: a comparison to conventional wound management
}

\author{
Tashi G. Khonglah*, Bhaskar Borgohain, Wanlamkupar Khongwir, Kashif A. Ahmed
}

\begin{abstract}
Department of Orthopaedics and Trauma, The North Eastern Indira Gandhi Regional Institute of Health and Medical Sciences, Shillong, Meghalaya, India
\end{abstract}

Received: 19 October 2020

Revised: 05 December 2020

Accepted: 05 December 2020

\author{
*Correspondence: \\ Dr. Tashi G. Khonglah, \\ E-mail: tashigalen@gmail.com
}

Copyright: () the author(s), publisher and licensee Medip Academy. This is an open-access article distributed under the terms of the Creative Commons Attribution Non-Commercial License, which permits unrestricted non-commercial use, distribution, and reproduction in any medium, provided the original work is properly cited.

\begin{abstract}
Background: Open fractures and traumatic wounds constitute a major health problem. Amongst the armamentarium of wound care products available, negative pressure wound therapy (NPWT) is a modality that has transformed wound care and has been recommended for treating all kinds of acute and chronic wounds.

Methods: This prospective randomised comparative study was conducted at a tertiary care hospital in Northeast India. 30 patients were included in this study over a period of 24 months commencing from January 2018. The patients consisted of two groups of 15 each, the first group comprised patients who underwent treatment using NPWT and the second group was treated using standard wound therapy (SWT). The endpoint taken was a granulated wound or a wound ready for split skin grafting (SSG).

Results: The mean wound size difference between the NPWT group and the SWT group on day nine was $13 \pm 7.17 \mathrm{~mm}$ and $4.53 \pm 0.99 \mathrm{~mm}$, respectively. Likewise, on day nine, $11(73.3 \%)$ patients in the group treated using NPWT had no positive bacterial cultures compared to $8(53.3 \%)$ patients on SWT. The estimated cost of materials for each NPWT dressing change was roughly INR₹ 3446 (US\$ 45.57).

Conclusions: NPWT is not a magic bullet and will not replace the basic methods of wound treatment such as wound debridement, infection control and ensuring adequate blood supply. Nevertheless, NPWT remains an integral part of the current scenario in wound care management and is cost effective under the condition that it accelerates wound healing when compared to traditional treatment.
\end{abstract}

Keywords: Negative pressure wound therapy, Wound care, Musculoskeletal injury, Open fracture

\section{INTRODUCTION}

Open fractures and traumatic wounds constitute a significant health problem. In addition to the pain and suffering, the failure of the wounds to heal cause an immense social and financial burden. Important to the success in the management of such wounds is the knowledge of the armamentarium of wound care products available. With many new methods of wound dressings introduced every now and then, there are approximately 1500 dressing types available for use by clinician in the United States. ${ }^{1}$ Though most types of dressings have been found to be less successful in relation to cost and efficacy, an exception to this is NPWT. ${ }^{2}$

Since the 1940s, negative pressure utilising various forms of drains were used for treating wounds. ${ }^{3}$ The treatment technique for open wounds based on negative pressure was developed in Germany and the United States during the 1990s. ${ }^{4,5}$ Known by other names such as vacuum-assisted closure (VAC) or micro deformational wound therapy (MDWT), the generic English language name NPWT is widely used. The treatment is based on the application of an evenly distributed local negative pressure applied to the wound surface. The open wound is covered with a dressing 
and sealed with an air-tight film. This dressing is then connected by means of a set of suction tubes to a microprocessor controlled vacuum unit that is capable of providing controlled level of continuous or intermittent sub atmospheric pressure. Most commonly, $80-125 \mathrm{mmHg}$ of negative pressure is used. The fluid suctioned from the wound is then collected in a canister in the control unit. ${ }^{6}$

NPWT has revolutionised wound care and has been recommended for treating all kinds of acute and chronic wounds. This modality of treatment has been proven to stimulate local angiogenesis, thereby increasing blood flow. This results in enhanced granulation formation, which decreases the surface area of the wound. ${ }^{7}$ In addition, NPWT reduces the number of dressing changes and can also be applied at bedside. The treatment duration varies from days to months, depending on the aim of the treatment and the nature of the wound. The negative pressure can be applied until granulation tissue develops or the local conditions allow an additional surgical procedure like a skin graft or a flap cover.

The purpose of this study was to evaluate the results of NPWT in the management of open musculoskeletal wounds, compared with conventional methods. To the best of our knowledge, this is the first study on cost evaluation for the Indian population.

\section{METHODS}

This prospective randomised comparative study was conducted at the North Eastern Indira Gandhi regional institute of health and medical sciences, a tertiary care hospital at Shillong in Northeast India. 30 patients admitted in the department of orthopaedics were included in this study over a period from January 2018 to December 2019. The first group comprised of 15 patients who underwent treatment using NPWT and the second group of another 15 patients who were treated using SWT. This study was approved by the medical ethics committee of the hospital.

The inclusion criteria for patients in the study were those above 18 years of age and were diagnosed with open musculoskeletal wounds of the extremities. These were patient's with grade II and grade III fractures (Gustilo and Anderson classification). Patients who were listed in the exclusion criteria were diabetics, those with coagulopathies, chronic use of steroids, malignancies, osteomyelitis and those with peripheral arterial disease of the lower extremities.

On admission, the patients were subjected to routine hematological investigations including a complete blood count, erythrocyte sedimentation rate, random blood sugar, and they were also screened for HIV, HbSAg and HCV. All patients involved in the study had to undergo an initial wound debridement in the operation theatre before commencement of either dressing procedures (Figure 1).

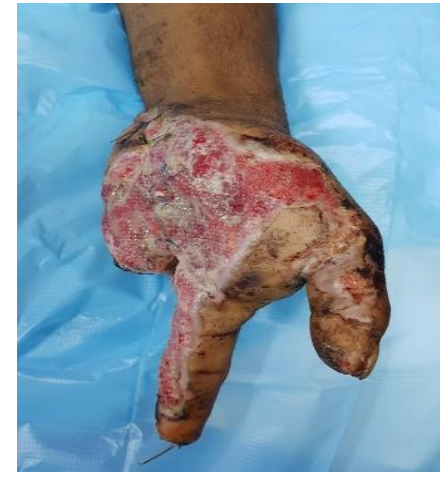

Figure 1: Wound on the left hand following initial debridement.

For patients who were treated using NPWT, following debridement and preparation of the wound bed, the surrounding skin was kept thoroughly dry. This was followed by the application of a sterile open pore foam (400-600 microns) that was shaped according to the configuration of the wound (Figure 2). The wound was then sealed using an adhesive drape through which a $5 \mathrm{~mm}$ rectangular opening was made at the center to which a length of tubing was connected to a $500 \mathrm{ml}$ canister attached to the vacuum unit. The pump was then set to deliver an intermittent negative suction pressure at 125 mmHg (Figure 3). Each cycle was set for 7 minutes (5 minutes, on and 2 minutes, off). These dressing were changed every 72 hours.

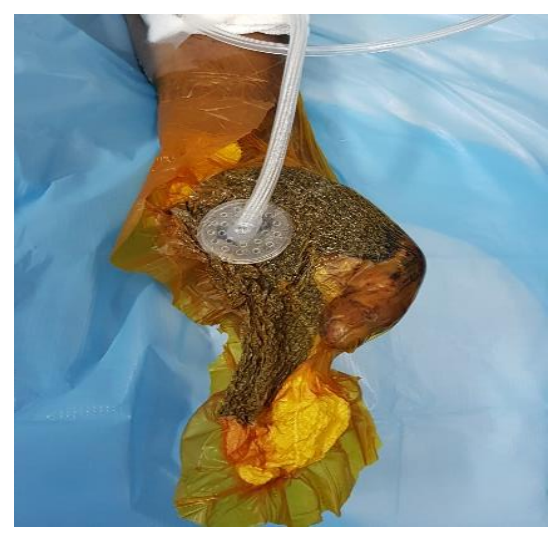

Figure 2: Application of a sterile open pore foam shaped according to the configuration of the wound and sealed using an adhesive drape.

Patients who were treated using the standard wound therapy also underwent initial wound debridement followed by dressing of the wound with povidone-iodine $(5 \%)$ and saline-soaked gauzes. Unlike NPWT, these dressings were changed daily.

In both group of patients, swabs for bacterial culture were obtained from the wound just before debridement then on day 3, day 6 and on day 9. Concurrently, measurements of the wound sizes were recorded on these days (Figure 4). Postoperatively, all patients initially received intravenous 
antibiotics in the form of $3^{\text {rd }}$ generation cephalosporins (cefuroxime $750 \mathrm{mg}$ I.V. thrice a day) and an aminoglycoside (amikacin $500 \mathrm{mg}$ I.V. twice daily). They were then altered according to microbiological culture and sensitivity reports. Antibiotics were continued till complete wound healing. The endpoint taken was a granulated wound or a wound ready for split skin grafting (SSG) or healing by secondary intention spontaneously whichever was earlier (Figure 5 and 6).

All dressings were performed only by the authors involved in this study. SPSS 22.0 software (SPSS Inc, Chicago, IL) was used for statistical analysis of the results obtained.

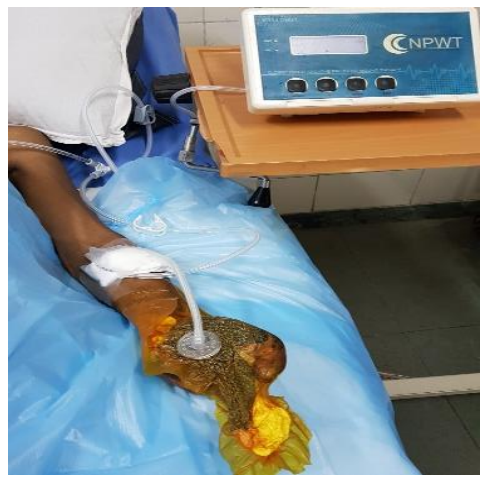

Figure 3: The machine was set to deliver an intermittent negative suction pressure at $125 \mathrm{mmHg}$.

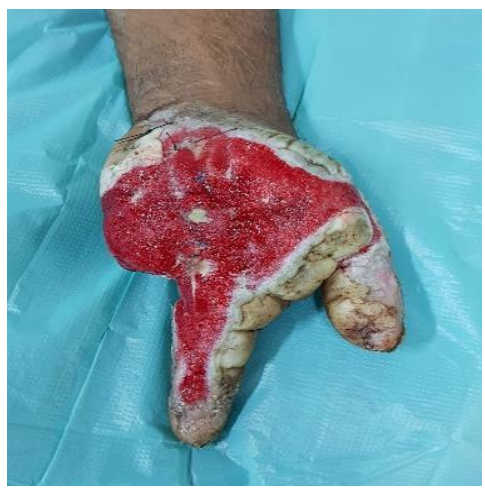

Figure 4: The wound as it appeared on day 9 of therapy.

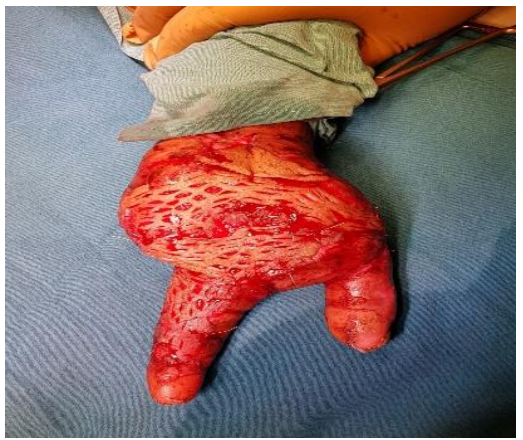

Figure 5: The wound following the application of a split thickness skin graft.

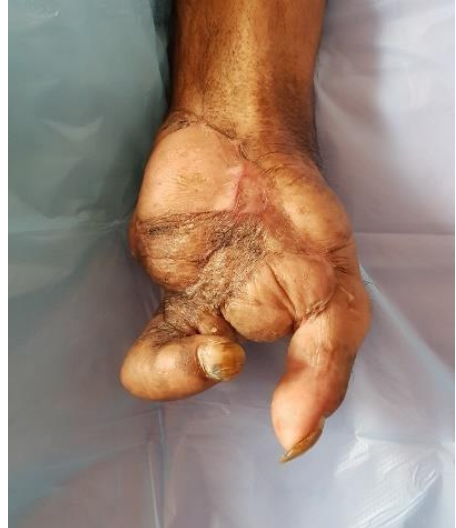

Figure 6: Final appearance of the healed wound at the time of the patients discharge.

\section{RESULTS}

The mean patient age in the study was found to be $36 \pm 15$ years. $27(90 \%)$ patients were males. The most common mode of injury was a road traffic accident with 21 (70\%) patients involved. This was followed by a fall from height where there were $5(16.7 \%)$ patients and $4(13.3 \%)$ patients who sustained a machinery injury. Of the 30 patients, 15 were grade IIIA injuries. 8 patients sustained a grade IIIB injury, 5 were documented as grade II while the remaining 2 were grade IIIC injuries. These gradings were according to the Gustilo and Anderson classification.

When comparing the reduction in wound size with the type of treatment method, it was noted that there was a significant shrinkage in the size of the wound from day 0 to day 9 in the NPWT group when compared to the SWT group (Table 1). The mean wound size difference between NPWT group and SWT group on day nine was found to be $13 \pm 7.17 \mathrm{~mm}$ and $4.53 \pm 0.99 \mathrm{~mm}$, respectively. This was found to be statistically significant (Table 2).

Table 1: The difference in wound size form day 0 to day 9.

\begin{tabular}{|lll|}
$\begin{array}{l}\text { Wound size } \\
(\mathbf{m m})\end{array}$ & $\begin{array}{l}\text { NPWT }(\mathbf{n}=15) \\
(\%)\end{array}$ & $\begin{array}{l}\text { SWT }(\mathbf{n}=15) \\
(\%)\end{array}$ \\
\hline $\mathbf{1 - 5}$ & 0 & $9(60)$ \\
\hline $\mathbf{5 . 1 - 1 0}$ & $6(40)$ & $6(40)$ \\
\hline $\mathbf{1 0 . 1 - 1 5}$ & $5(33.3)$ & 0 \\
\hline $\mathbf{1 5 . 1 - 2 0}$ & $3(20)$ & 0 \\
\hline $\mathbf{2 0 . 1}$ & $1(6.7)$ & 0 \\
\hline
\end{tabular}

Table 2: The mean wound size difference between NPWT and SWT on day 9.

\begin{tabular}{|lll|}
\hline Variables & $\begin{array}{l}\text { NPWT } \\
(\mathbf{n}=15)\end{array}$ & $\begin{array}{l}\text { SWT } \\
(\mathbf{n}=15)\end{array}$ \\
\hline $\begin{array}{l}\text { Mean wound size } \\
\text { difference }\end{array}$ & $13 \pm 7.17$ & $4.53 \pm 0.99$ \\
\hline
\end{tabular}

$* \mathrm{P}$ value $<0.05$ 
Table 3: Bacterial growth on day 0 and day $9(n=30)$.

\begin{tabular}{|lllll|}
\multirow{2}{*}{ Variables } & \multicolumn{2}{l}{ NPWT $(\mathbf{n = 1 5})$} & \multicolumn{2}{l|}{ SWT (n=15) } \\
& Day 0 & Day 9 & Day 0 & Day 9 \\
\hline Present & $12(80)$ & $4(26.7)$ & $12(80)$ & $8(53.3)$ \\
\hline Absent & 3 & 11 & 3 & 7 \\
& $(20)$ & $(73.3)$ & $(20)$ & $(46.7)$ \\
\hline
\end{tabular}

In terms of bacterial growth at day 9 of the therapy, it was noted that there was a significant decrease of bacterial growth in the NPWT group. At day 9, 11 (73.3\%) patients in the group treated using NPWT had no positive bacterial cultures while $8(53.3 \%)$ patients on SWT still had bacterial presence (Table 3). In spite of bacterial growths, there were no deep infections noted.

There were no labor charges for either treatment modalities and dressing material for the SWT group were provided free of cost. Materials for the NPWT group had to be purchased, they included the following items-a sterilized dressing combi kit comprising a large sized dressing foam $(14.6 \times 25.7 \times 3.3 \mathrm{~cm}), 4$ pieces of adhesive polyurethane drapes and a single PVC drainage suction tube. In addition to the dressing kit, a sterile canister (500 $\mathrm{ml}$ ), a bacterial filter and a vacuum suction unit were required for the treatment. The vacuum suction unit was however, provided free of cost. The estimated cost of materials required for each dressing change performed for NPWT was INR₹ 3446 (US\$45.57) while the complete cost of treatment comprising four dressing changes for each patient was placed at INR₹ 13784 (US\$ 182.26). The U.S. Dollar exchange rate was 0.013 (as of June $27^{\text {th }}$, 2020).

\section{DISCUSSION}

Based on the encouraging results of NPWT performed on a couple of patients, the authors decided to administer this form of treatment on a larger group of patients. Furthermore, the absence of a department of plastic surgery at our hospital prompted us to consider this modality. NPWT was therefore intended as a form of "bridge therapy" for these patients wanting plastic surgery intervention, therefore decreasing their length of hospital stay by speeding up wound healing.

During 1900-1940, most wounds were treated with gauze dressings, a practice that has not changed since Egyptian times. The following three decades (1950-1970) saw the first innovations in wound dressing, such as the development of tulle gras (1950) and the theory of moist wound healing (1962) with the first film dressing available in 1971. During the next two decades (1980-2000), a plethora of wound dressings came in to the market, including the first antimicrobials. By the turn of the century, there was greater progress in wound management. ${ }^{8}$ Collectively, there are now approximately 1500 dressing types available for use by clinician in the United States. ${ }^{1}$
With traumatic injuries becoming a major cause of death and disability world-wide. ${ }^{9}$ The patient population with musculoskeletal wounds is ever increasing and poses a significant challenge to the treating surgeons regarding wound healing, coverage and reconstruction. There is delayed wound healing on account of the substantial soft tissue defects caused by these open wounds. The goal of wound care is ultimately to regenerate an intact epithelial barrier expeditiously and therefore, successful therapy should be based on knowledge of the wound etiology and the different features of wound care products available. ${ }^{6}$ Despite advances in the treatment regimen which include a vast armamentarium of wound care products, these soft tissue injuries continue to pose a great challenge to the surgeon.

Based on the pioneering work of Argenta and Morykwas, et al there is a large class of wound care systems being used today or in the process of being developed that have been broadly referred to as NPWT devices. ${ }^{5,10}$ NPWT has been proven to enhance granulation tissue formation over previously cleansed wounds, by stimulating local angiogenesis which increases local blood flow. This local increase in vascularity results in an influx of fibroblasts, which diminish the surface area of the wound by approximating its margins. ${ }^{11} \mathrm{With}$ the increase in the blood flow following application of sub atmospheric pressure, it was noted that bacterial colonization of the wound tissues also decreased. ${ }^{5}$

Our study noted a statistically significant mean wound size difference between NPWT group and SWT group on day 9. The results were found to be $13.0 \pm 7.17 \mathrm{~mm}$ and $4.53 \pm 0.99 \mathrm{~mm}$, respectively. $6(40 \%)$ patients of the NPWT group achieved a decrease in size of 1 to $10 \mathrm{~mm}$ in the wound from day 0 to day 9 as compared to $100 \%$ patients in the SWT group. A decrease in wound size of more than $10.1 \mathrm{~mm}$ was seen in $8(60 \%)$ of patients in the NPWT group. Our findings were comparable to those of Morykwas and Banwell et al. ${ }^{5,12}$

Mechanical forces have been used outside of medicine for centuries to create tissue. Women in Ethiopia use ceramic plates of increasing diameter to expand the lower lip while some in Thailand use metal rings to stretch out their necks. ${ }^{1}$ The importance of mechanics in repair was popularized by Julius Wolff (1836-1902), a German surgeon, who recognized that bone morphology adapts to applied mechanical loads. ${ }^{13}$ The interaction of wound healing and mechanical forces is analogous to where forces have been applied in other areas of the human body. It was Urschel et al who proposed that negative pressure had mechanical effect on the wound bed. ${ }^{14}$ Micro deformation, caused by suction devices with an interface has been recognized as having the capacity of applying tensile forces to the wound surface. ${ }^{1}$ The force of this collapse is transmitted to the wound margins, thus drawing them close together. 
Our study also documented the bacterial growth on day 0 was present in $12(80 \%)$ patients each in either group. However, by day 9 only $4(26.7 \%)$ patients treated by NPWT still had positive cultures whereas, 8 (53.3\%) patients in the SWT group remained positive for bacterial growth. Similar results showing a gradual reduction in the bacterial growth from the infected wounds following the use of NPWT have been demonstrated by the studies of Morykwas and Banwell et al. ${ }^{5,12}$ In spite of bacterial growths, there were no deep infections noted. Blum and colleagues compared the rate of deep infection between NPWT and conventional dressing treatment groups as $8.4 \%$ and $20.6 \%$, respectively. ${ }^{15}$ The polyurethane drape is semipermeable, allowing a small amount of air to enter the system, thereby preventing a fluid lock and allowing continuous evacuation of fluid. Toxins from the wound, bacteria, and exudate can be removed with the fluids. ${ }^{1}$

In terms of expenditure incurred, the average cost of supplies for NPWT required for each dressing change in our study was US\$ 45.57. This amount spent was found to be far lesser when compared to the study by Kim et al who quoted the daily cost of dressing as US\$ 94.01. ${ }^{16}$ In another study by Kamamoto et al, the mean cost of treatment for the NPWT group was US\$ 872.59 whereas the total amount spent in our study was almost five times lesser at a modest US\$ $182.26 .{ }^{17}$ Our ability to curtail expenditure can be explained by the absence of labor charges while performing these dressings and the waiver of daily rental charges for the vacuum suction device. Other explanations by which we were able to keep our costs marginal was by using a large sized dressing foam $(14.6 \times 25.7 \times 3.3 \mathrm{~cm})$ which could be divided into four quadrants. The unused slices of the foam were kept sterilized for the next dressing change. Nevertheless, these calculations made in one country cannot be generalized in other countries. ${ }^{6}$ Although various NPWT systems are currently available in the market, their costs have discouraged their use in many hospitals.(18) This has led to many researchers innovating other low-cost methods to perform negative pressure dressings. ${ }^{17-19}$

NPWT dressings are laborious as compared to standard wound dressings. However, the reduced number of dressing changes (every 72 hours) for NPWT helped alleviate these problems. Common difficulties encountered while performing these NPWT dressings was during the removal of the open pore foam which tended to adhere to the underlying tissue in turn causing pain. This was relieved by adding normal saline mixed with a local anesthetic to the dressing foam. Another drawback was the presence of external fixators, the pins may make complete sealing of the wound difficult to achieve, and leaks may therefore occur in the suction system. Robert et al had recommended the use of bone wax for sealing these air leaks. ${ }^{11}$

Though the main limitation of our study is the small number of patients, the findings have been replicated by several others. ${ }^{6}$ Patients on SWT required numerous dressings which was laborious and prolonged their hospital stay further leading to poor compliance. Contrary to SWT, the value of debridement and negative pressure wound therapy was found to be a safe and effective treatment method for open musculoskeletal injuries and encourages a superior and speedier proportion of healed wounds.

\section{CONCLUSION}

NPWT has transformed wound care and has been advocated for treating all kinds of acute and chronic wounds. This modality of treatment has been proven to stimulate local angiogenesis, thereby increasing blood flow and enhancing the formation of granulation tissue. However, NPWT is not a magic bullet and will not replace the basic methods of wound treatment such as wound debridement, infection control and ensuring adequate blood supply. Though there are many technological innovations and advancement of medical therapies, it is important to be mindful of developing more cost-effective approaches to currently utilized therapies. Advanced wound care products such as growth factors, bioengineered skin, and dermal scaffolds still remain out of reach. NPWT will therefore remain an integral part of the current scenario in wound care management and would be cost-effective under the condition that it accelerates wound healing when compared to traditional treatment.

\section{ACKNOWLEDGEMENTS}

This study was funded through an intra-mural grant from The North Eastern Indira Gandhi regional institute of health and medical sciences. The authors wish to thank Dr. Star Pala, associate professor, department of community medicine, NEIGRIHMS, Shillong for his valuable assistance in the statistical analysis of this manuscript.

Funding: Funding sources by Intra-mural grant from The North Eastern Indira Gandhi regional institute of health and medical sciences

Conflict of interest: None declared

Ethical approval: The study was approved by the institutional ethics committee

\section{REFERENCES}

1. Huang C, Leavitt T, Bayer LR, Orgill DP. Effect of negative pressure wound therapy on wound healing. Curr Probl Surg. 2014;51(7):301-31.

2. El-Sabbagh AH. Negative pressure wound therapy: An update. Chin J Traumatol. 2017;20(2):103-7.

3. Fay MF. Drainage systems. Their role in wound healing. AORN J. 1987;46(3):442-55.

4. Morykwas MJ, Argenta LC, Shelton-Brown EI, McGuirt W. Vacuum-assisted closure: a new method for wound control and treatment: animal studies and basic foundation. Ann Plast Surg. 1997;38(6):553-62.

5. Argenta LC, Morykwas MJ. Vacuum-assisted closure: a new method for wound control and 
treatment: clinical experience. Ann Plast Surg. 1997;38(6):563-76.

6. Vikatmaa $P$, Juutilainen $\mathrm{V}$, Kuukasjärvi $\mathrm{P}$, Malmivaara A. Negative Pressure Wound Therapy: a Systematic Review on Effectiveness and Safety. Eur J Vasc Endovasc Surg. 2008;36(4):438-48.

7. Maillard H. Negative pressure therapy: NPT. Ann Dermatol Venereol. 2015;142(8-9):498-501.

8. Harding K. Innovation and Wound Healing. J Wound Care. 2015;24(4b):7-13.

9. Joshipura M, Mock C, Goosen J, Peden M. Essential Trauma Care: strengthening trauma systems round the world. Injury. 2004;35(9):841-5.

10. Schaum KD. A new Medicare Part B wound care policy. Adv Skin Wound Care. 2001;14(5):238-40.

11. Robert N. Negative pressure wound therapy in orthopaedic surgery. Orthop Traumatol Surg Res OTSR. 2017;103(1S):99-103.

12. Banwell P, Withey S, Holten I. The use of negative pressure to promote healing. Br J Plast Surg. 1998;51(1):79.

13. Frost HM. Wolff's Law and bone's structural adaptations to mechanical usage: an overview for clinicians. Angle Orthod. 1994;64(3):175-88.

14. Urschel JD, Scott PG, Williams HT. The effect of mechanical stress on soft and hard tissue repair; a review. Br J Plast Surg. 1988;41(2):182-6.

15. Blum ML, Esser M, Richardson M, Paul E, Rosenfeldt FL. Negative pressure wound therapy reduces deep infection rate in open tibial fractures. $\mathbf{J}$ Orthop Trauma. 2012;26(9):499-505.

16. Kim JJ, Franczyk M, Gottlieb LJ, Song DH. Costeffective Alternative for Negative-pressure Wound Therapy. Plast Reconstr Surg Glob Open. 2017;5(2).

17. Kamamoto F, Lima ALM, de Rezende MR, MattarJunior R, de Camargo Leonhardt M, Kojima KE et al. A new low-cost negative-pressure wound therapy versus a commercially available therapy device widely used to treat complex traumatic injuries: a prospective, randomized, non-inferiority trial. Clinics. 2017;72(12):737-42.

18. Dorafshar AH, Franczyk M, Gottlieb LJ, Wroblewski $\mathrm{KE}$, Lohman RF. A prospective randomized trial comparing subatmospheric wound therapy with a sealed gauze dressing and the standard vacuumassisted closure device. Ann Plast Surg. 2012;69(1):79-84.

19. Perez D, Bramkamp M, Exe C, von Ruden C, Ziegler A. Modern wound care for the poor: a randomized clinical trial comparing the vacuum system with conventional saline-soaked gauze dressings. Am J Surg. 2010;199(1):14-20.

Cite this article as: Khonglah TG, Borgohain B, Khongwir W, Ahmed KA. Clinical outcome and cost analysis of negative pressure wound therapy in extremity wounds: a comparison to conventional wound management. Int J Res Orthop 2021;7:97102 . 